\title{
Comprehensive multigene mutation spectra of breast cancer patients from Northeast China obtained using the Ion Torrent sequencing platform
}

\author{
CHUNNI FAN ${ }^{1}$, NING LIU ${ }^{1}$, SHULIN FAN ${ }^{1}$, ZHAOYING YANG $^{1}$, NING YE ${ }^{2}$ and KEREN WANG ${ }^{1}$ \\ ${ }^{1}$ Department of Breast Surgery, China-Japan Union Hospital of Jilin University, Changchun, Jilin 130033; \\ ${ }^{2}$ Wuhan PrimBio Medical Laboratory, PrimBio Gene Biotechnology, Wuhan, Hubei 430000, P.R. China
}

Received November 2, 2018; Accepted July 4, 2019

DOI: $10.3892 /$ or.2019.7253

\begin{abstract}
The objectives of the present study were to obtain the multigene mutation spectra of female breast cancer patients in Northeast China, to explore the correlation between mutations and clinicopathological characteristics, and to identify genetic mutations that correlate with the prognosis and survival of breast cancer patients. An Ion Torrent sequencing platform was used to detect mutations, including 31 known gene mutations associated with breast cancer, in 621 specimens from 286 breast cancer patients. A total of 286 patients were enrolled in this study. Eleven harmful/pathogenic gene mutations were found in $54.2 \%(155 / 286)$ of the patients, and 179 somatic nonsynonymous mutations were detected. Approximately 5.6\% (16/286) of the patients carried two or more gene mutations. Among the 11 pathogenic gene mutations, those in PIK3CA were the most common and were detected in $65.4 \%$ (117/179) of the patients; TP53 gene mutations were the second most common and were detected in $20.7 \%$ (37/179) of the patients. Additional mutations were found in AKT (14/179; 7.8\%) and PTEN (4/179; 2.2\%), and mutations in the remaining 7 genes were each detected in approximately $0.6 \%$ (1/179) of the patients. Excluding 6 cases of breast ductal carcinoma in situ, the remaining 280 breast cancer cases were divided into four groups by molecular subtype, and the mutation frequencies of the 11 breast cancer-associated genes differed among the four groups. Furthermore, these 280 breast cancer cases were divided into two clinically relevant therapeutic groups: The $\mathrm{HR}^{+} / \mathrm{HER} 2^{-}$and triple-negative groups. The triple-negative group had a high frequency of TP53 mutations (21.8\%) and a low frequency of PIK3CA mutations $(21.8 \%)$, whereas the HR+/HER2- group harbored TP53 mutations at a low frequency $(10.1 \%)$ and PIK3CA mutations
\end{abstract}

Correspondence to: Dr Keren Wang, Department of Breast Surgery, China-Japan Union Hospital of Jilin University, 126 Xiantai Street, Changchun, Jilin 130033, P.R. China

E-mail: kerenwang88@163.com

Key words: next-generation sequencing, breast cancer, HR-positive, triple-negative, Ion Torrent sequencing platform at a high frequency (50.0\%). Cancerous, paracancerous, and normal tissues were collected from 72 patients and subjected to next-generation sequencing. The types and frequencies of somatic nonsynonymous mutations differed among the three studied tissue types, reflecting the genetic heterogeneity of different tissues from the same individual. In addition, tissues from 70 patients (excluding 2 patients with ductal carcinoma in situ) were divided into four groups according to molecular subtype, and the gene mutation frequencies in cancerous, paracancerous, and normal tissues differed among the four groups. After normalization, gene mutations were detected at a higher rate in cancerous tissues than in paracancerous and normal tissues in all groups, except for the HER2-positive group (which had a small sample size). In addition, Cox multivariate analyses of clinicopathological data, gene sequencing results, and 5-year survival rates of the 286 patients showed that gene mutations in the PTEN-PI3K/AKT signaling pathway were independently associated with a poor prognosis $(\mathrm{P}<0.05)$. In conclusion, mutations in the PTEN-PI3K/AKT signaling pathway may be valuable in the prediction of the prognosis and survival of breast cancer patients.

\section{Introduction}

Approximately 1.3 million new cases of breast cancer are diagnosed annually worldwide, and an estimated 450,000 patients die from this disease each year (1). The incidence is $3-4 \%$ per year, and patients are being diagnosed at younger ages each year (2). In China, nearly 200,000 women are diagnosed with breast cancer every year, and breast cancer ranks first among the five most commonly diagnosed malignancies in women (3). Moreover, since 2013 it has been the fourth leading cause of cancer-related death among women. Although the precise causes of breast cancer remain unclear, the primary risk factors include environmental factors, hormonal effects, and importantly, genetic factors (4-8). Epidemiological studies have found that $5-10 \%$ of breast cancer cases are hereditary and associated with inherited genetic mutations (9). At present, breast cancer treatment is primarily based on the diagnosis of clinical stage, pathological type and molecular subtype, which includes the expression status of estrogen receptor (ER), progesterone receptor (PR), and human epidermal growth 
factor 2 receptor (HER2) as well as the proliferation index Ki67 (10,11). However, conventional clinicopathological diagnoses have limited accuracy and specificity, making precise classification of individual breast cancer patients difficult. The effectiveness of specific treatments can vary among patients classified as having breast cancer of the same clinical stage, pathological classification and molecular subtype. Therefore, personalized and precise treatments must be developed based on the heterogeneity of breast cancer $(12,13)$.

In recent years, targeted cancer therapy has developed rapidly, resulting in the availability of precision medicine. Basic research and clinical studies have gradually identified and validated many gene mutations associated with targeted cancer therapy. The study of gene mutations relies on advancements in gene detection techniques, such as Sanger sequencing, pyrosequencing, and real-time fluorescent polymerase chain reaction (PCR), which typically permit detection of mutations in individual genes or exons (14). By comparison, next-generation sequencing (NGS) technology utilizes massively parallel sequencing (MPS) to sequence millions or even billions of DNA fragments in parallel, which enables the identification of as many as hundreds of tumor-associated genes through examination of all exons and the whole genome $(15,16)$. NGS has broad potential for the detection of tumor-related gene mutations $(17,18)$.

Ion Torrent sequencing is an NGS technology based on semiconductor chip technology and uses the same principle of complementary base pairing. This approach uses an ion sensor to detect local $\mathrm{pH}$ changes caused by the release of hydrogen ions $\left(\mathrm{H}^{+}\right)$during DNA polymerization. This chemically encoded information is transferred directly into digital information; therefore, bases are interpreted in real time, allowing sequences of DNA fragments to be obtained rapidly. Compared to other sequencing technologies, Ion Torrent sequencing does not require fluorescent labeling, reducing the need for expensive optics and offering incomparable advantages in terms of equipment costs, sequencing speed, and sequencing costs (19-21). In the present study, we utilized the Ion Torrent sequencing platform and the PrimBio Breast Cancer Panel, which is a NGS gene panel targeting breast cancer-related genes, including i) $B R C A 1 / 2$, the most studied genes in inherited breast cancer ii), other candidate genes for inherited breast cancer, and iii) susceptibility genes that may be sporadically mutated in breast cancer. With coverage of 31 genes, the PrimBio Breast Cancer Panel is the most comprehensive breast cancer gene panel available and provides rapid target selection within formalin-fixed, paraffin-embedded samples.

As the development and progression of breast cancer are highly variable, drug responses can differ among various tumor cells of the same patient. The purpose of the present study was to obtain the multigene mutation spectra of female patients with breast cancer in Northeast China, in order to explore the correlation between mutations and clinicopathological characteristics and to identify genetic mutations that might be useful for predicting the prognosis and survival of breast cancer patients. We used the Ion Torrent sequencing platform (PrimBio Medical Laboratory, PrimBio Genes Biotechnology, Wuhan, China) to detect mutations in all coding exons of 31 genes in 621 specimens from 286 breast cancer patients, and 91 blood samples from the enrolled patients were collected as a control group. The harmful/pathogenic gene mutations (somatic nonsynonymous mutations) in each tissue were identified, and their correlations with clinicopathological data and survival outcomes were analyzed. The ultimate purpose of this study was to identify genetic mutations that can be used to predict the prognosis and survival of breast cancer patients.

\section{Materials and methods}

Sample collection. All enrolled breast cancer patients were treated at the China-Japan Union Hospital of Jilin University from October 2010 to April 2013 and did not receive any neoadjuvant therapy before surgery. The specimens were all obtained from the hospital tissue bank. We analyzed breast cancer tissues from 286 patients and blood samples from 91 patients. For 72 patients, four tissue samples were collected at the same time, including cancerous tissue, paracancerous tissue (within $3 \mathrm{~cm}$ of the cancerous tissue), normal tissue (normal tissue located more than $3 \mathrm{~cm}$ from the cancerous tissue), and blood. All experiments were approved by the Ethics Committee of the China-Japan Union Hospital of Jilin University, and an informed consent form was signed by each enrolled patient. The clinicopathological data for the 286 patients enrolled in this study are presented in Table I.

Sequencing and analysis. Genomic DNA was extracted from tissue or blood samples from the breast cancer patients, and a library was generated using the PrimBio breast cancer gene panel, which covers the complete coding regions of 31 genes associated with breast cancer. Samples were sequenced using an Ion Proton sequencing platform, and the obtained sequencing results were analyzed using Human Genome Build 19 (Hg19, The Genome Reference Consortium Human Genome Build 37 (GRCh 37) ) as a reference. Breast cancer-specific mutations were identified using PrimBio by comparing DNA sequences in tumor tissue to those in blood from the same patient, and then, tumor-specific mutations were identified using StrandNGS software (https://www.strand-ngs.com), which can detect harmful/pathogenic mutations by comprehensively evaluating scores predicted by the Scale-Invariant Feature Transform (SIFT), Polyphen2, Likelihood Ratio Test (LRT), Mutation Taster, Mutation Assessor, and Functional Analysis Through Hidden Markov Models (FATHMM) features. After synonymous mutations were identified, all the other mutations were defined as nonsynonymous mutations. By examining four samples from each patient, mutations identified in blood samples were defined as germline mutations, while those found only in the other three tissues were defined as somatic mutations. All somatic mutations were annotated using the Catalogue of Somatic Mutations in Cancer (COSMIC) database (http://cancer.sanger.ac.uk/cosmic).

Data analysis and processing. Significant differences in the obtained data were identified by one-way analysis of variance (ANOVA), and mutations associated with the survival of breast cancer patients were identified by Kaplan-Meier survival analysis with a log rank test. Finally, multivariate analyses were performed using a Cox proportional hazard regression model to identify gene mutations independently associated with breast cancer prognosis. $\mathrm{P}<0.05$ indicated statistical significance. 
Table I. Clinicopathological data of the 286 breast cancer patients enrolled in this study.

\begin{tabular}{ll}
\hline Characteristics & Data n (\%) \\
\hline
\end{tabular}

Age (years)
$\leq 35$
$35-50$
$>50$

Anti-estrogen therapy

Yes

No

Number of births

0

1

2

$\geq 3$

Number of abortions

0
1
2
$\geq 3$

Tumor size

Primary cancer

$\leq 2 \mathrm{~cm}$

$2-5 \mathrm{~cm}$

$>5 \mathrm{~cm}$

Skin involvement

Lymph node metastasis

0

$\leq 3$

4-9

$\geq 10$

Type of pathology

Ductal carcinoma

Lobular carcinoma

Mucinous carcinoma

Hybrid

Vascular involvement

Yes

No

Expression of $P 53$

Yes

No

Ki67

$<14 \%$

$\geq 14 \%$

Molecular subtype (except primary cancer)

Luminal A

Luminal B

Her2 overexpression

Triple-negative

$110(38.5)$

82 (28.7)

$66(23.1)$

$28(9.8)$

$6(2.1)$

$148(51.7)$

$114(39.9)$

14 (4.9)

4 (1.4)

$140(49.0)$

$61(21.3)$

40 (14.0)

45 (15.7)

254 (88.9)

5 (1.7)

$6(2.1)$

$21(7.3)$

$124(43.4)$

$162(56.6)$

$171(59.8)$

115 (40.2)

$103(36.0)$

$183(64.0)$

$120(42.0)$
Table I. Continued..

\begin{tabular}{lc}
\hline Characteristics & Data n $(\%)$ \\
\hline Clinical stage & \\
Primary cancer & $6(2.1)$ \\
1 & $99(34.6)$ \\
2 & $92(32.2)$ \\
3 & $81(28.3)$ \\
4 & $8(2.8)$ \\
Recurrence risk & \\
Low & $9(3.1)$ \\
Moderate & $168(58.7)$ \\
High & $109(38.1)$ \\
\hline
\end{tabular}

Table II. Gene mutations according to the different histologic subtypes of the breast carcinoma cases.

\begin{tabular}{lcccc}
\hline $\begin{array}{l}\text { Mutation } \\
\text { (number })\end{array}$ & $\begin{array}{c}\text { Ductal } \\
(\mathrm{n}=254)\end{array}$ & $\begin{array}{c}\text { Lobular } \\
(\mathrm{n}=5)\end{array}$ & $\begin{array}{c}\text { Mucinous } \\
(\mathrm{n}=6)\end{array}$ & $\begin{array}{c}\text { Mixed } \\
(\mathrm{n}=21)\end{array}$ \\
\hline
\end{tabular}

PIK3CA (117)

TP53 (37)

AKT1 (14)

PTEN (4)

GATA3 (1)

$A T M(1)$

$B R C A 2$ (1)

BRCAI (1)

PALB2 (1)

RAD51D (1)

CHEK2 (1)

105
34
14
4
0
1
1
1
1
1
1

3
1
0
0
0
0
0
0
0
0
0

2

0

PIK3CA, phosphatidylinositol-4,5-bisphosphate 3-kinase catalytic subunit $\alpha$; TP53, tumor protein P53; AKT1, AKT serine/threonine kinase 1; PTEN, phosphatase and tensin Homolog; GATA3, GATA binding protein 3; ATM, ATM serine/threonine kinase; BRCA2, $B R C A 2$ DNA repair associated; $B R C A 1, B R C A 1$ DNA repair associated; PALB2, partner and localizer of BRCA2; RAD51D, RAD51 paralog D; CHEK2, checkpoint kinase 2.

\section{Results}

Gene mutations identified in the breast cancer patients. A total of 179 somatic nonsynonymous mutations in 11 harmful/pathogenic genes were detected (Table II). Approximately 54.2 and $5.6 \%$ of the patients carried one and multiple gene mutations, respectively. The two most frequently mutated genes were PIK3CA (39.2\%) and TP53 (12.9\%). In the PIK3CA gene, 117 pathogenic mutations (somatic nonsynonymous mutations) were detected in 112 breast cancer patients, and the distribution of these mutations is presented in Table III.
Distribution of mutation frequencies according to recurrence risk. According to the risk of recurrence, the patients were 
Table III. Mutation distribution among the exons of PIK3CA.

\begin{tabular}{lccc}
\hline mut_pos & $\begin{array}{c}\text { Case Freq, } \mathrm{n}(\%) \\
\mathrm{N}=286\end{array}$ & dbSNP & 1,000-genome MAF (\%) \\
\hline c.1258T>C:p.C420R & $1(0.3)$ & $\mathrm{rs} 121913272$ & 0 \\
c.1624G>A:p.E542K & $13(4.5)$ & $\mathrm{rs} 121913273$ & 0 \\
c.1633G>A:p.E545K & $23(8.0)$ & $\mathrm{rs} 104886003$ & 0 \\
c.1634A>G:p.E545G & $1(0.3)$ & $\mathrm{rs} 121913274$ & 0 \\
c.1635G>T:p.E545D & $2(0.7)$ & $\mathrm{rs} 121913275$ & 0 \\
c.1636C>A:p.Q546K & $1(0.3)$ & $\mathrm{rs} 121913286$ & 0 \\
c.1637A>G:p.Q546R & $1(0.3)$ & $\mathrm{rs397517201}$ & 0 \\
c.3140A>G:p.H1047R/L & $75(26.2)$ & $\mathrm{rs} 121913279$ & 0 \\
\hline
\end{tabular}

PIK3CA, phosphatidylinositol-4,5-bisphosphate 3-kinase catalytic subunit $\alpha$.

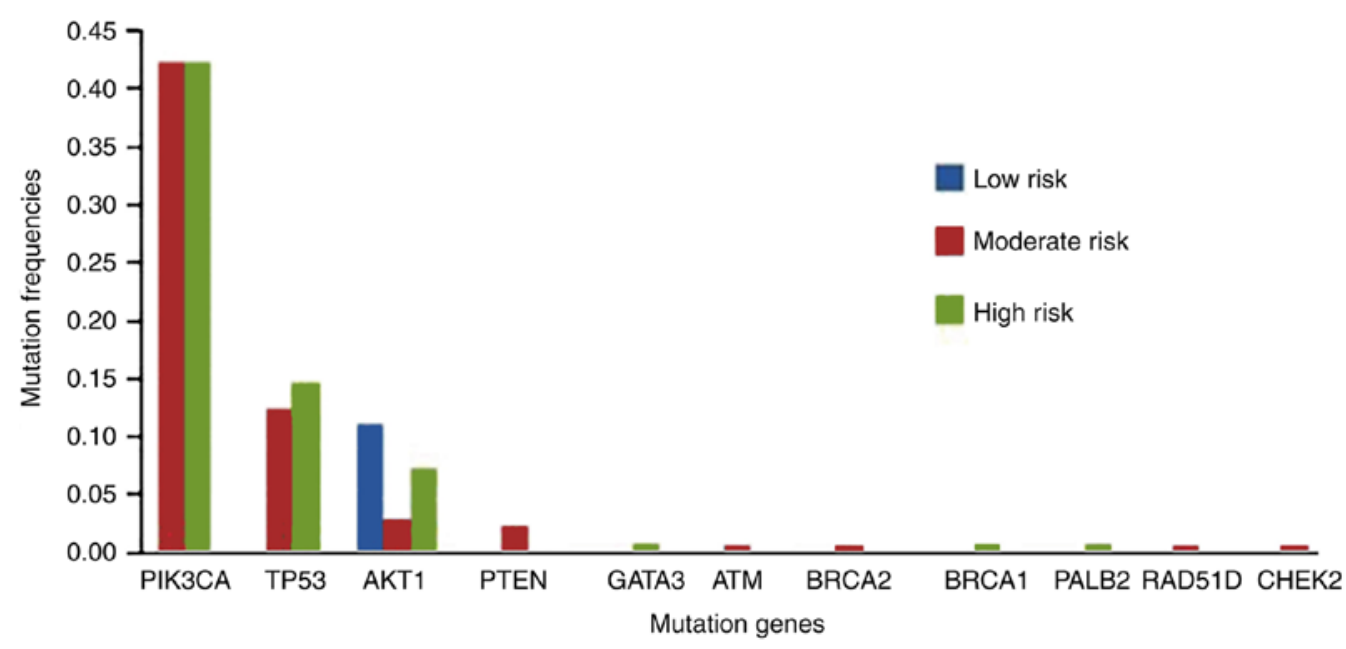

Figure 1. Distribution of the mutation detection rates in groups with differing risk of recurrence. PIK3CA, phosphatidylinositol-4,5-bisphosphate 3-kinase catalytic subunit $\alpha$; TP53, tumor protein P53; AKT1, AKT serine/threonine kinase 1; PTEN, phosphatase and tensin homolog; GATA3, GATA binding protein 3; ATM, ATM serine/threonine kinase; $B R C A 2, B R C A 2$ DNA repair associated; BRCA1, BRCA1 DNA repair associated; PALB2, partner and localizer of $B R C A 2 ; R A D 51 D, R A D 51$ paralog D; CHEK2, checkpoint kinase 2.
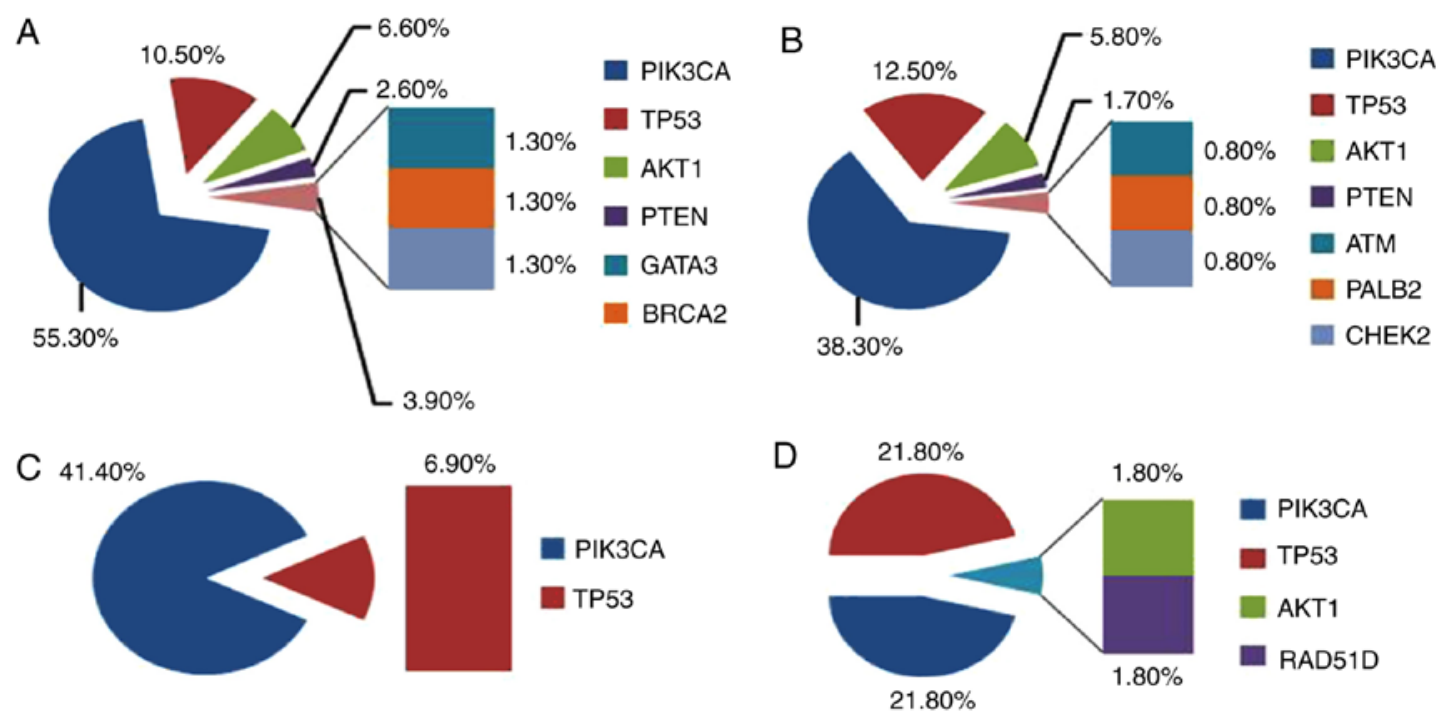

Figure 2. Gene mutation frequencies according to four molecular subtypes of breast cancer: (A) Luminal A, (B) Luminal B, (C) HER2-positive and (D) triple-negative. PIK3CA, phosphatidylinositol-4,5-bisphosphate 3-kinase catalytic subunit $\alpha$; TP53, tumor protein P53; AKT1, AKT serine/threonine kinase 1; PTEN, phosphatase and tensin Homolog; GATA3, GATA binding protein 3; ATM, ATM serine/threonine kinase; PALB2, partner and localizer of BRCA2; RAD51D, RAD51 paralog D; CHEK2, checkpoint kinase 2. 
Table IV. Comparison of the gene mutations in PIK3CA, TP53, AKT1 and PTEN between the $\mathrm{HR}^{+} / \mathrm{Her} 2^{-}$and triple-negative groups.

\begin{tabular}{lccc}
\hline Gene & $\begin{array}{c}\mathrm{HR}^{+} / \mathrm{Her} 2^{-} \\
\text {group }(\mathrm{n}=149)\end{array}$ & $\begin{array}{c}\text { Triple-negative } \\
\text { group }(\mathrm{n}=55)\end{array}$ & P-value \\
\hline PIK3CA & 73 & 12 & $<0.01$ \\
TP53 & 15 & 12 & $<0.05$ \\
AKT1 & 10 & 1 & $>0.05$ \\
PTEN & 4 & 0 & \\
GATA3 & 1 & 0 & \\
BRCA1 & 1 & 0 & \\
BRCA2 & 1 & 0 & \\
PALB2 & 1 & 0 & \\
RAD51D & 0 & 1 & \\
CHEK2(1) & 1 & 0 & $<0.01$ \\
Total & 107 & 26 & \\
\hline
\end{tabular}

PIK3CA, phosphatidylinositol-4,5-bisphosphate 3-kinase catalytic subunit $\alpha$; TP53, tumor protein P53; AKT1, AKT serine/threonine kinase 1; PTEN, phosphatase and tensin homolog; GATA3, GATA binding protein 3; ATM, ATM serine/threonine kinase; BRCA2, BRCA2 DNA repair associated; BRCA1, BRCA1 DNA repair associated; PALB2, partner and localizer of BRCA2; RAD51D, RAD51 paralog D; CHEK2, checkpoint kinase 2.

Table V. Gene mutations identified in 72 sets of cancerous, paracancerous, and normal tissues.

\begin{tabular}{lccc}
\hline Gene & $\begin{array}{c}\text { Cancerous } \\
\text { tissues }\end{array}$ & $\begin{array}{c}\text { Paracancerous } \\
\text { tissues }\end{array}$ & $\begin{array}{c}\text { Normal } \\
\text { tissues }\end{array}$ \\
\hline PIK3CA & $28(20)$ & $8(1)$ & $10(3)$ \\
TP53 & 6 & 0 & 0 \\
AKT1 & 7 & 1 & 0 \\
GATA3 & 1 & 1 & 0 \\
ATM & 0 & 1 & 0 \\
PTEN & 0 & 0 & 3 \\
BRCA2 & 0 & 0 & 1 \\
Total & 42 & 11 & 14 \\
\hline
\end{tabular}

PIK3CA, phosphatidylinositol-4,5-bisphosphate 3-kinase catalytic subunit $\alpha$; TP53, tumor protein P53; AKT1, AKT serine/threonine kinase 1; PTEN, phosphatase and tensin homolog; GATA3, GATA binding protein 3; ATM, ATM serine/threonine kinase; BRCA2, BRCA2 DNA repair associated.

divided into low-risk ( $\mathrm{n}=9)$, moderate-risk ( $\mathrm{n}=168)$, and high-risk $(\mathrm{n}=109)$ groups. The mutation distributions for the three groups are shown in Fig. 1. More genetic mutations were detected in the moderate- and high-risk groups, while only one mutation site in the $A K T 1$ gene was detected in the low-risk group.

Gene mutation frequencies according to molecular subtype. The Luminal A, Luminal B, HER2-positive, and triple-negative

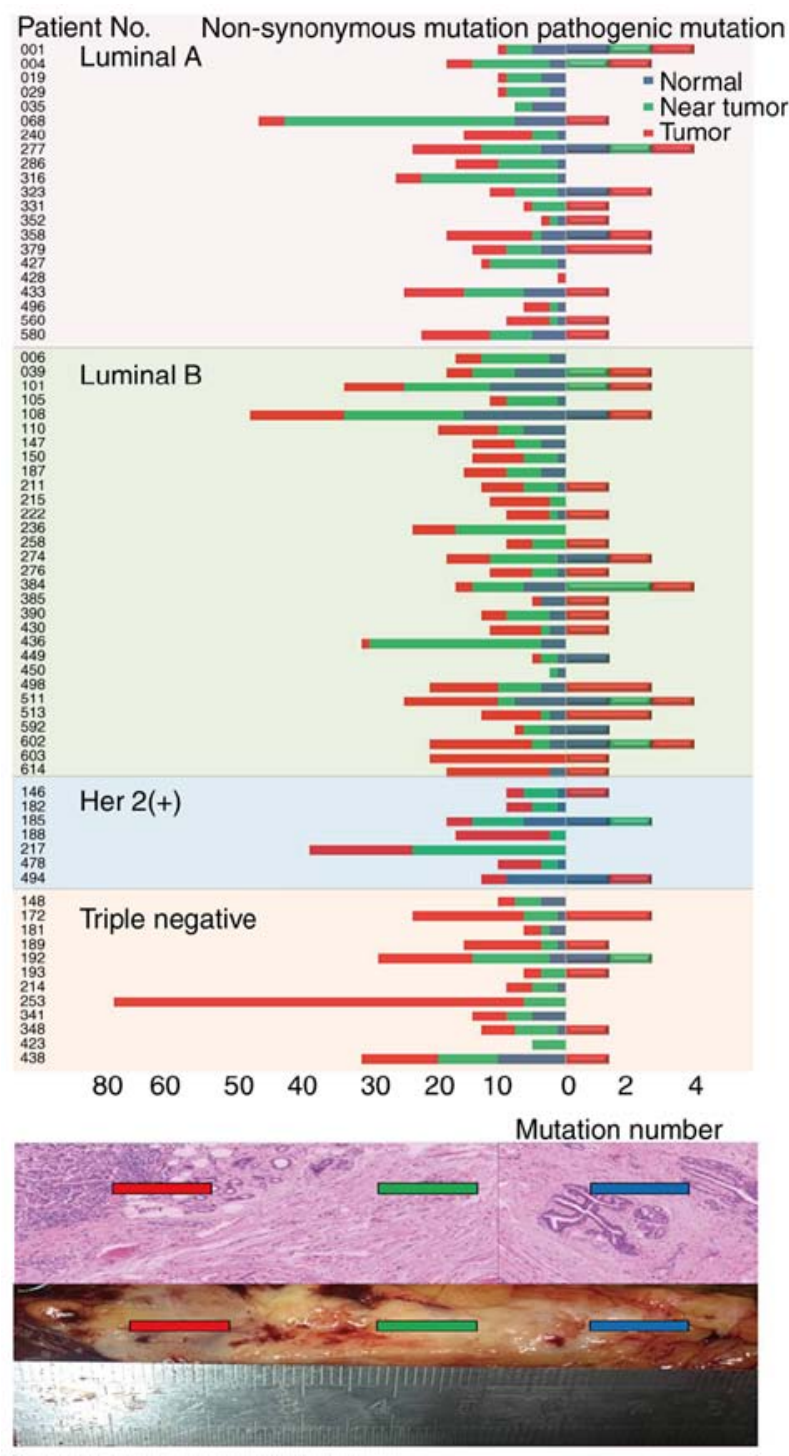

Figure 3. Somatic nonsynonymous mutations and pathogenic mutations identified in 70 breast cancer patients. The middle row is representative hematoxylin and eosin staining images of the three types of tissues, including cancerous tissue, paracancerous tissue (within $3 \mathrm{~cm}$ of cancerous tissue), and normal tissue. The bottom panel shows the general pathology of the three tissues.

subtype groups included $76,120,29$, and 35 , respectively. As shown in Fig. 2, the percentages of patients who carried gene mutations differed among the molecular subtype groups. In the Luminal A subtype group (Fig. 2A), the mutation rate of PIK3CA was the highest at $55.3 \%$, followed by those of TP53 (10.5\%) and AKT1 (6.6\%). In the Luminal B subtype group (Fig. 2B), the PIK3CA mutation rate was the highest at $38.3 \%$, followed by those of TP53 (12.5\%) and AKT1 (5.8\%). In the HER2-positive subtype group (Fig. 2C), the frequency of mutations in the PIK3CA gene was $41.4 \%$ and that in the TP53 gene was only $6.9 \%$. In the triple-negative subtype group (Fig. 2D), the PIK3CA and TP53 genes had the highest mutation frequencies at $21.8 \%$ each. In the $\mathrm{HR}^{+} / \mathrm{HER} 2$ group, $59.8 \%$ of the mutations were found in $29 \%$ of the genes, while in the HR-HER 2 group, $14.5 \%$ of the mutations were found in only $12.9 \%$ of the genes, which was significantly different. Furthermore, PIK3CA and TP53 mutations showed significantly different frequencies between $\mathrm{HR}^{+} / \mathrm{HER} 2-$ and triple-negative tumors (Table IV). 
Table VI. Correlation of mutation types with breast cancer subtypes in 70 breast cancer patients from whom cancerous, paracancerous and normal tissues were obtained.

\begin{tabular}{llccccc}
\hline & & \multicolumn{3}{c}{ Molecular subtype } & & \\
\cline { 3 - 5 } Tissues & Mutation type & $\begin{array}{c}\text { Luminal A } \\
(\mathrm{n}=21)\end{array}$ & $\begin{array}{c}\text { Luminal B } \\
(\mathrm{n}=30)\end{array}$ & $\begin{array}{c}\text { HER2 } \\
(\mathrm{n}=7)\end{array}$ & $\begin{array}{c}\text { Triple-negative } \\
(\mathrm{n}=12)\end{array}$ & P-value \\
\hline Cancerous tissues & Nonsynonymous & 7 & 14 & 4 & 4 & 0.584 \\
& Pathogenic & 14 & 16 & 3 & 8 & 0.813 \\
Paracancerous tissues & Nonsynonymous & 18 & 24 & 6 & 11 & 1 \\
& Pathogenic & 3 & 6 & 1 & 11 & 0.358 \\
\hline
\end{tabular}

Gene mutations identified in 72 sets of cancerous, paracancerous, and normal tissues. The gene mutation spectra differed among cancerous, paracancerous, and normal tissues (Table V). The somatic non-synonymous mutations and pathogenic mutations detected in tissues from 70 breast cancer patients after removal of two primary cancer patients are shown in Fig. 3. Compared with normal and paracancerous tissues, tumor cells are disorderly arranged and more nuclear pleomorphism and divisional nucleus were observed in the breast cancer tissues (Fig. 3). A total of 914 somatic nonsynonymous mutations were detected in these 70 patients, and the cancer tissues harbored the highest number of gene mutations. The correlations between gene mutations and molecular subtypes in the three tissue types were analyzed, and the results showed that nonsynonymous and pathogenic mutations had no significant differences among the different molecular subtypes (Table VI). We also found that some of the eight common PIK3CA gene mutations were repeatedly detected in the same patient (Table VII). A frameshift mutation in the $B R C A 2$ gene was identified in this patient, and this frameshift is likely to cause truncation of BRCA2 (Fig. 4), resulting in a protein lacking the last 374 amino acids. This truncation is predicted to impair the binding of $C D K$ and $R A D 51$, which have important functions during DNA repair (Fig. 5).

Correlations between mutations in the PTEN/PI3K/AKT signaling pathway and the 5-year survival rate. Cox multivariate analysis showed that patients with gene mutations in the PTEN/PI3K/AKT signaling pathway had a poor prognosis $(\mathrm{P}=0.044$; Fig. 6A) We further analyzed the correlations between gene mutations and molecular subtypes of breast cancer, and the results showed that patients in the triple-negative group with gene mutations of the PTEN/PI3K/AKT signaling pathway had a poor prognosis $(\mathrm{P}=0.038$; Fig. 6B).

\section{Discussion}

Breast cancer development and progression are highly variable, leading to genetic heterogeneity (22) and variable drug responses among tumor cells of the same patient (23). In the present study, the multigene mutation spectra of female breast cancer patients in Northeast China were investigated to
Table VII. Analysis of PIK3CA gene mutations detected in 72 sets of cancerous, paracancerous, and normal tissues.

\begin{tabular}{lccc}
\hline $\begin{array}{l}\text { PIK3CA } \\
\text { mutation }\end{array}$ & $\begin{array}{c}\text { Cancerous } \\
\text { tissues }\end{array}$ & $\begin{array}{c}\text { Paracancerous } \\
\text { tissues }\end{array}$ & $\begin{array}{c}\text { Normal } \\
\text { tissues }\end{array}$ \\
\hline $\begin{array}{l}\text { Single detection } \\
\text { Repeat detection }\end{array}$ & 14 & 1 & 3 \\
\hline
\end{tabular}

PIK3CA, phosphatidylinositol-4,5-bisphosphate 3-kinase catalytic subunit $\alpha$.

examine correlations between mutations and clinicopathological characteristics and identify genetic mutations potentially useful for predicting the prognosis and survival of breast cancer patients. The Ion Torrent sequencing platform was used to detect gene mutations and based on comparisons with previous studies of this platform, the results of our study are accurate and reliable $(24,25)$.

Our study showed that $54.2 \%$ of breast cancer patients carried somatic nonsynonymous mutations, which is slightly lower than the percentage reported by a previous study $(62.1 \%)(26)$. The mutation rate of PIK3CA was higher than that of TP53 (39.2 vs. 12.9\%), which is consistent with previous results obtained in Chinese patients (35.2 vs. 15.2\%) (27) but different from the rates in other countries (31.7 vs. 38.8\%) (26). The mutation rate of AKT1 (4.9\%) was slightly lower in our study than previously reported in other countries $(6 \%)$, while the mutation rate of PTEN (1.4\%) was the same (1.4\%) (26). The detected PIK3CA gene mutation rate is among the highest in breast cancer reaching $25-40 \%$. In our study, the PIK3CA mutation detection rate was $39.2 \%$, similar to rates reported worldwide (28-30). The frequency of the PIK3CA c.3140A $>\mathrm{G}$ (p.H1047R) mutation was high in our cohort and similar to the rate previously reported (28). Further analysis showed that the gene mutation rates differed among the low, moderate, and high recurrence risk groups. The gene mutation spectra for the moderate- and high-risk groups were more complicated, and their mutation frequencies were significantly higher than those for the low-risk group. Our study demonstrated the practicality of using the mutation spectrum for predicting the recurrence 

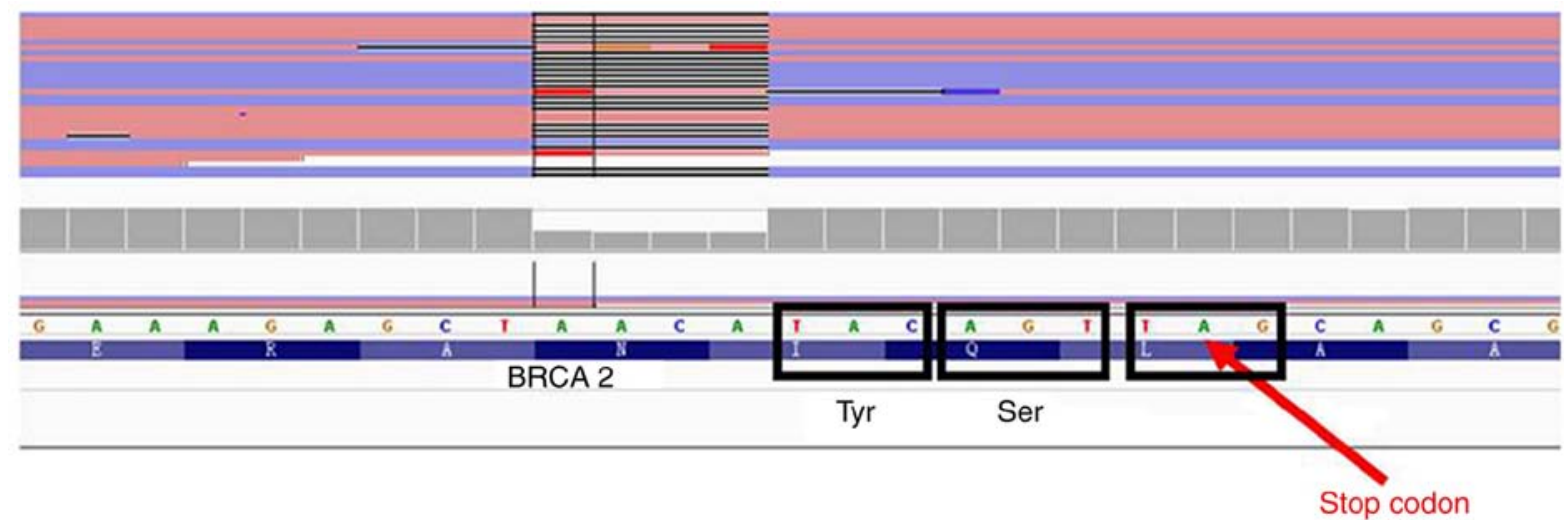

Figure 4. Variants in patient 370: BRCA2: NM_000059: exon23: c.9070_9073del: p. N3024fs. Top panel is the sequencing results at the variant location displayed in Integrative Genomics Viewer. The individual reads are shown in pink (forward orientation), or blue (reverse orientation) bars. Missing nucleotides are shown with black lines. The middle panel is sequencing results summarized as grey columns. Shorter columns implicate the deletion of nucleotides. The bottom panel is nucleotide and amino acid sequences of the wild-type gene at the location. The codons in the variants are circled in black boxes and the amino acids sequence of the variant are shown below the codon. BRCA2, BRCA2 DNA repair associated.

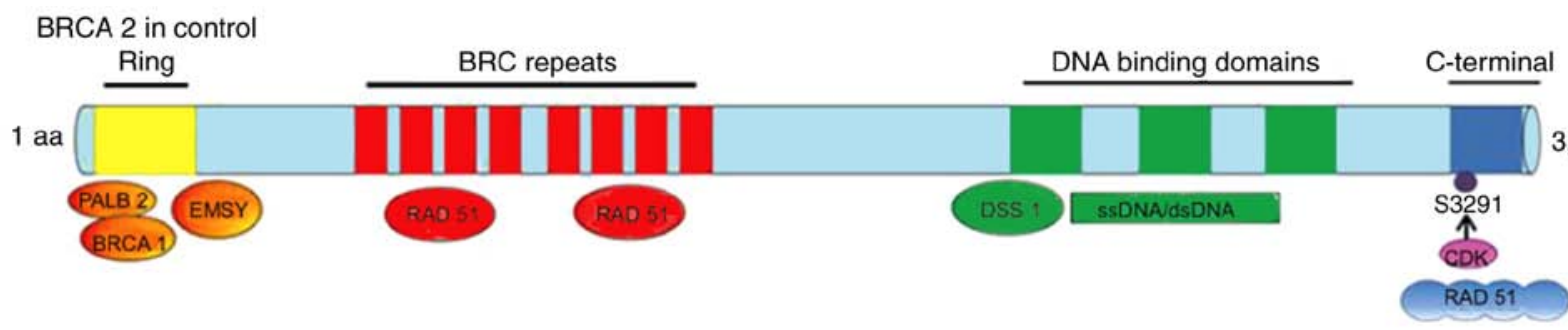

BRCA 2 in patient 370

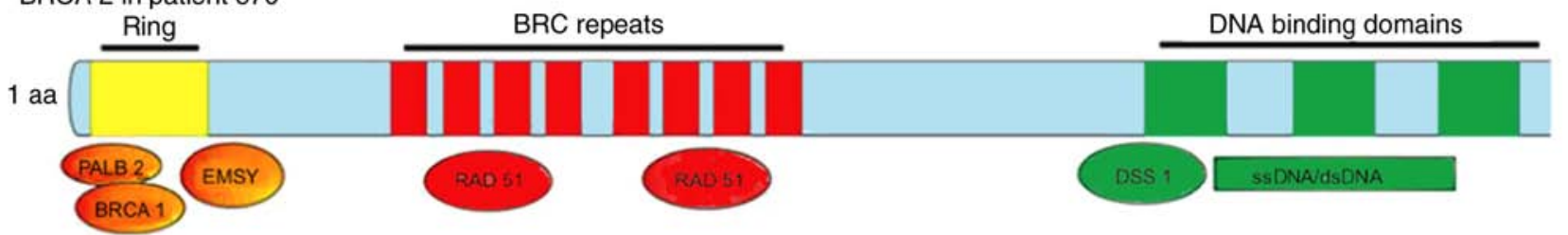

Figure 5. Truncation likely impairs the binding of $C D K$ and $R A D 51 . B R C A 2, B R C A 2$ DNA repair associated; RAD51D, RAD51 paralog D; CHEK2, checkpoint kinase 2.
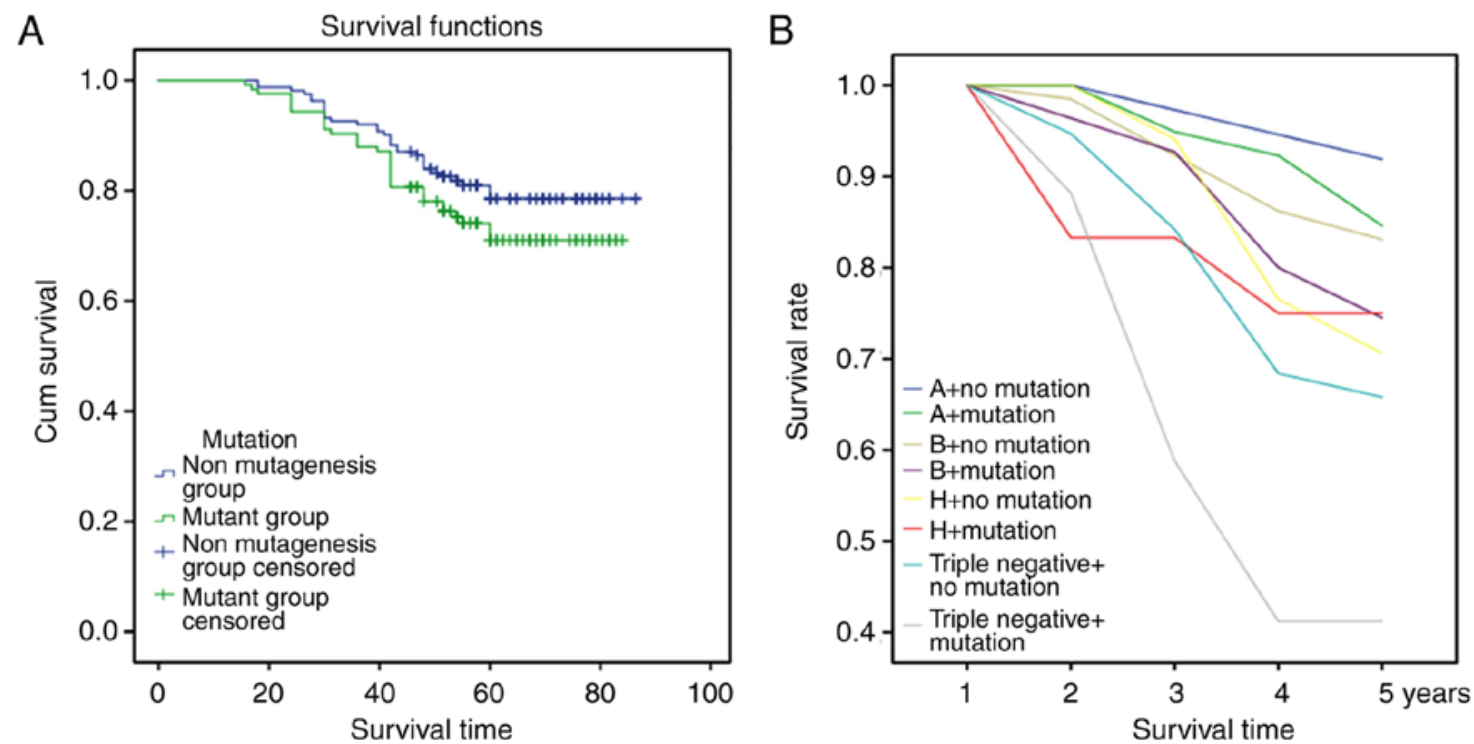

Figure 6. (A) Correlations between mutations in the PTEN/PI3K/AKT signaling pathway and the 5-year survival rate among 286 breast cancer patients. (B) Correlations between mutations in the PTEN/PI3K/AKT signaling pathway and the 5-year survival rate according to the four molecular subtypes of breast cancer. A, Luminal A; B, Luminal B; H, HER2-positive. 
risk after surgery. The spectra of gene mutations also varied among the different molecular subtypes of breast cancer. Although the sample size for the HER2-positive subtype was small $(n=31)$ and mutations were identified in only two genes, PIK3CA and TP53, the mutations were detected at a frequency of $8.3 \%$ (15 of 179), which is similar to the rate previously reported (26).

The gene mutation spectra differed between the $\mathrm{HR}^{+} / \mathrm{HER} 2^{-}$and HR/HER2 ${ }^{-}$groups (31). In the HR ${ }^{+} / \mathrm{HER} 2$ group, clinical immunohistochemistry results for $\mathrm{p} 53$ expression were positive for all breast cancer, indicating that breast cancer patients without p53 protein function due to TP53 gene mutation were concentrated in the triple-negative subtype.

In our study, a total of 914 somatic nonsynonymous mutations were detected in 70 patients, and the cancerous tissues harbored the highest number of gene mutations. A total of $67 \mathrm{harmful} /$ pathogenic mutations were detected in these tissues, and cancerous tissues contained the highest number of mutated genes. Overall, $96 \%$ of patients were found to have somatic nonsynonymous mutations in all three tissue types, while only $7.7 \%$ of patients were diagnosed with somatic pathogenic mutations in all 3 tissues, and $34.2 \%$ of patients had pathogenic mutations in only cancerous tissue. In all four patient groups, the mutation rates in cancerous tissue were higher than those in paracancerous and normal tissues after normalization.

Mutations in genes associated with the PTEN-PI3K/AKT signaling pathway are closely related to breast cancer development $(32,33)$. Based on follow up of all enrolled patients, the 5-year survival rate of the 286 patients was $77.3 \%$, which is similar to a previously reported rate (34). We also found that gene mutations associated with the PTEN-PI3K/AKT signaling pathway were independent factors affecting the survival rate as well as predictors of poor prognosis for breast cancer patients, and these findings differed from those of previous studies (35-37), providing new evidence for evaluating the prognosis of patients with breast cancer. In addition, we analyzed correlations of specific mutations and the number of mutations with the 5-year survival rate and found no significant differences.

Although our study primarily focused on somatic nonsynonymous mutations, we found an interesting and unreported genetic mutation in all four tissues of patient number 370 . We validated these mutations by sequencing and will continue to explore this mutation status through the following steps: i) Examine $B R C A 2 \mathrm{mRNA}$ and protein levels in samples from patient 370 ; ii) characterize the interaction between truncated $B R C A 2$ (if expressed) and $R A D 51$ and $C D K$; iii) transfect $B R C A 2^{-/-}$and $B R C A 2^{+/-}$cell lines with truncated $B R C A 2$; and iv) characterize the DNA integrity in cells from patient 370 . These studies are in progress.

In summary, we analyzed the harmful/pathogenic gene mutation spectra of breast cancer cases in Northeast China through second-generation sequencing and provided new insights into these spectra. The population coverage in our study was high, and the results differed from those of studies conducted in Europe and the United States $(26,38,39)$; Japan, South Korea and other Asian areas $(40,41)$; and southern China (42). In the context of the global promotion of precision medicine, our study presents valuable information for the clinical treatment of breast cancer patients in Northeast China and other similar Asian areas.

\section{Acknowledgements}

The authors thank the Tissue Bank of the China-Japan Union Hospital of Jilin University for their generous help.

\section{Funding}

This research was supported by the Science \& Technology Development Project of Jilin Province (grant no. 20160101033JC).

\section{Availability of data and materials}

We declared that materials described in the manuscript, including all relevant raw data, will be freely available to any scientist wishing to use them for non-commercial purposes, without breaching participant confidentiality.

\section{Authors' contributions}

CF and NL conducted the experiments, collected the data and analyzed the data. SF and ZY were major contributors in interpreting the results and writing the manuscript. NY and $\mathrm{KW}$ helped in designing the study, analyzing the data and revising the manuscript. All authors read and approved the final manuscript and agree to be accountable for all aspects of the research in ensuring that the accuracy or integrity of any part of the work are appropriately investigated and resolved.

\section{Ethics approval and consent to participate}

All experiments were approved by the Ethics Committee of the China-Japan Union Hospital of Jilin University, and an informed consent form was signed by each enrolled patient.

\section{Patient consent for publication}

Not applicable.

\section{Competing interests}

The authors declare that they have no competing interests.

\section{References}

1. Arnold M, Karim-Kos HE, Coebergh JW, Byrnes G, Antilla A, Ferlay J, Renehan AG, Forman D and Soerjomataram I: Recent trends in incidence of five common cancers in 26 European countries since 1988: Analysis of the European Cancer Observatory. Eur J Cancer 51: 1164-1187, 2015.

2. Brenner DR, Brockton NT, Kotsopoulos J, Cotterchio M, Boucher BA, Courneya KS, Knight JA, Olivotto IA, Quan ML and Friedenreich CM: Breast cancer survival among young women: A review of the role of modifiable lifestyle factors. Cancer Causes Control 27: 459-472, 2016.

3. Chen W, Zheng R, Baade PD, Zhang S, Zeng H, Bray F, Jemal A, Yu XQ and He J: Cancer statistics in China, 2015. CA Cancer J Clin 66: 115-132, 2016.

4. Gray JM, Rasanayagam S, Engel C and Rizzo J: State of the evidence 2017: An update on the connection between breast cancer and the environment. Environ Health 16: 94, 2017. 
5. Makarem N, Chandran U, Bandera EV, Parekh N: Dietary fat in breast cancer survival. Annu Rev Nutr 33: 319-348, 2013.

6. Brewer HR, Jones ME, Schoemaker MJ, Ashworth A and Swerdlow AJ: Family history and risk of breast cancer: An analysis accounting for family structure. Breast Cancer Res Treat 165: 193-200, 2017.

7. Zhang B, Shu XO, Delahanty RJ, Zeng C, Michailidou K, Bolla MK, Wang Q, Dennis J, Wen W, Long J, et al: Height and breast cancer risk: Evidence from prospective studies and mendelian randomization. J Natl Cancer Inst 107: djv219, 2015.

8. Kwong A, Shin VY, Ho JC, Kang E, Nakamura S, Teo SH, Lee AS, Sng JH, Ginsburg OM, Kurian AW, et al: Comprehensive spectrum of BRCA1 and BRCA2 deleterious mutations in breast cancer in Asian countries. J Med Genet 53: 15-23, 2016.

9. Stadler ZK, Schrader KA, Vijai J, Robson ME and Offit K: Cancer genomics and inherited risk. J Clin Oncol 32: 687-698, 2014.

10. Smith DR, Quinlan AR, Peckham HE, Makowsky K, Tao W, Woolf B, Shen L, Donahue WF, Tusneem N, Stromberg MP, et al: Rapid whole-genome mutational profiling using next-generation sequencing technologies. Genome Res 18: 1638-1642, 2008.

11. Gilissen C, Hehir-Kwa JY and Thung DT: Genome sequencing identifies major causes of severe intellectual disability. Nature 511: 344-347, 2014

12. Kittaneh M, Montero AJ and Gluck S: Molecular profiling for breast cancer: A comprehensive review. Biomark Cancer 5: 61-70, 2013.

13. Goldhirsch A, Wood WC, Coates AS, Gelber RD, Thürlimann B and Senn HJ; Panel members: Strategies for subtypes-dealing with the diversity of breast cancer: Highlights of the St. Gallen International Expert Consensus on the primary therapy of early breast cancer 2011. Ann Oncol 22: 1736-1747, 2011.

14. Marziali A and Akeson M: New DNA sequencing methods. Annu Rev Biomed Eng 3: 195-223, 2001.

15. Xu X, Hou Y, Yin X, Bao L, Tang A, Song L, Li F, Tsang S $\mathrm{Wu} \mathrm{K}, \mathrm{Wu} \mathrm{H}$, et al: Single-cell exome sequencing reveals single-nucleotide mutation characteristics of a kidney tumor. Cell 148: 886-895, 2012.

16. Hou Y, Song L, Zhu P, Zhang B, Tao Y, Xu X, Li F, Wu K, Liang J, Shao D, et al: Single-cell exome sequencing and monoclona evolution of a JAK2-negative myeloproliferative neoplasm. Cell 148: 873-885, 2012.

17. Clinical and laboratory standards institute. Nucleic acid sequencing methods in diagnostic laboratory medicine. Approved guideline-Second Edition CLSI document MM09. A2. Wayne, PA: CLSI, 2014.

18. Sotiriou $\mathrm{C}$ and Pusztai L: Gene-expression signatures in breast cancer. N Engl J Med 360: 790-800, 2009.

19. Roukos D and Ku CS: Clinical cancer genome and precision medicine. Ann Surg Oncol 19: 3646-3650,2012.

20. Damerla RR, Chatterjee B, Li Y, Francis RJ, Fatakia SN and Lo CW: Ion Torrent sequencing for conducting genome-wide scans for mutation mapping analysis. Mamm Genome 25: $154-156,2014$

21. Meldrum C, Doyle MA and Tothill RW: Next-generation sequencing for cancer diagnostics: A practical perspective. Clin Biochem Rev 32: 177-195, 2011.

22. Vogelstein B, Papadopoulos N, Velculescu VE, Zhou S, Diaz LA Jr and Kinzler KW: Cancer genome landscapes. Science 339: 1546-1558, 2013 .

23. Almendro V and Fuster G: Heterogeneity of breast cancer: Etiology and clinical relevance. Clin Transl Oncol 13: 767-773, 2011.

24. Fujita S, Masago K, Takeshita J, Okuda C, Otsuka K, Hata A, Kaji R, Katakami N and Hirata Y: Validation of an Ion Torren sequencing platform for the detection of gene mutations in biopsy specimens from patients with non-small-cell lung cancer. PLoS ONE 10: e0130219, 2015.

25. Zanella I, Merola F, Biasiotto G, Archetti S, Spinelli E and Di Lorenzo D: Evaluation of the Ion Torrent PGM sequencing workflow for the routine rapid detection of BRCA1 and BRCA2 germline mutations. Exp Mol Pathol 102: 314-320, 2017.
26. Roy-Chowdhuri S, de Melo Gagliato D, Routbort MJ, Patel KP, Singh RR, Broaddus R, Lazar AJ, Sahin A, Alvarez RH, Moulder S, et al: Multigene clinical mutational profiling of breast carcinoma using next-generation sequencing. Am J Clin Pathol 144: 713-721, 2015.

27. Bai X, Zhang E, Ye H, Nandakumar V, Wang Z, Chen L, Tang C, $\mathrm{Li} \mathrm{J}, \mathrm{Li} \mathrm{H}$, Zhang W, et al: PIK3CA and TP53 gene mutations in human breast cancer tumors frequently detected by ion torrent DNA sequencing. PLoS One 9: e99306, 2014.

28. Klarenbeek S, van Miltenburg MH and Jonkers J: Genetically engineered mouse models of PI3K signaling in breast cancer. Mol Oncol 7: 146-164, 2013.

29. Samuels $Y$ and Waldman T: Oncogenic mutations of PIK3CA in human cancers. Curr Top Microbiol Immunol 347: 21-41, 2010.

30. Bhat-Nakshatri P, Goswami CP, Badve S, Magnani L, Lupien M and Nakshatri H: Molecular insights of pathways resulting from two common PIK3CA mutations in breast cancer. Cancer Res 76: 3989-4001, 2016

31. Boyault S, Drouet Y, Navarro C, Bachelot T, Lasset C, Treilleux I, Tabone E, Puisieux A and Wang Q: Mutational characterization of individual breast tumors: TP53 and PI3K pathway genes are frequently and distinctively mutated in different subtypes. Breast Cancer Res Treat 132: 29-39, 2012.

32. Tserga A, Chatziandreou I, Michalopoulos NV, Patsouris E and Saetta AA: Mutation of genes of the PI3K/AKT pathway in breast cancer supports their potential importance as biomarker for breast cancer aggressiveness. Virchows Arch 469: 35-43, 2016.

33. Lee MS, Jeong MH, Lee HW, Han HJ, Ko A, Hewitt SM, Kim JH, Chun KH, Chung JY, Lee C, et al: PI3K/AKT activation induces PTEN ubiquitination and destabilization accelerating tumourigenesis. Nat Commun 6: 7769, 2015.

34. Fan L, Strasser-Weippl K, Li JJ, St Louis J, Finkelstein DM, $\mathrm{Yu} \mathrm{KD}$, Chen WQ, Shao ZM and Goss PE: Breast cancer in China. Lancet Oncol 15: e279-e289, 2014

35. Koundouros N and Poulogiannis G: Phosphoinositide 3-kinase/Akt signaling and redox metabolism in cancer. Front Oncol 8: 160, 2018

36. Miller TW, Rexer BN, Garrett JT and Arteaga CL: Mutations in the phosphatidylinositol 3-kinase pathway: Role in tumor progression and therapeutic implications in breast cancer. Breast Cancer Res 13: 224, 2011.

37. Papadavid E, Korkolopoulou P, Levidou G, Saetta AA, Papadaki T, Siakantaris M, Nikolaou V, Oikonomidi A, Chatziandreou I, Marinos L, et al: In situ assessment of PI3K and PTEN alterations in mycosis fungoides: Correlation with clinicopathological features. Exp Dermatol 23: 931-933, 2014

38. Bozhanov SS, Angelova SG, Krasteva ME, Markov TL, Christova SL, Gavrilov IG and Georgieva EI: Alterations in p53, BRCA1, ATM, PIK3CA, and HER2 genes and their effect in modifying clinicopathological characteristics and overall survival of Bulgarian patients with breast cancer. J Cancer Res Clin Oncol 136: 1657-1669, 2010.

39. Pereira B, Chin SF, Rueda OM, Vollan HK, Provenzano E, Bardwell HA, Pugh M, Jones L, Russell R, Sammut SJ, et al: The somatic mutation profiles of 2,433 breast cancers refines their genomic and transcriptomic landscapes. Nat Commun 7: 11479, 2016.

40. Kato T, Park JH, Kiyotani K, Ikeda Y, Miyoshi Y and Nakamura $Y$ : Integrated analysis of somatic mutations and immune microenvironment of multiple regions in breast cancers. Oncotarget 8: 62029-62038, 2017.

41. Kim JY, Lee E, Park K, Park WY, Jung HH, Ahn JS, Im YH and Park YH: Clinical implications of genomic profiles in metastatic breast cancer with a focus on TP53 and PIK3CA the most frequently mutated genes. Oncotarget 8: 27997-28007, 2017.

42. Yang X, Wu J, Lu J, Liu G, Di G, Chen C, Hou Y, Sun M, Yang W, Xu X, et al: Identification of a comprehensive spectrum of genetic factors for hereditary breast cancer in a Chinese population by next-generation sequencing. PLoS One 10: e0125571, 2015. 